\title{
A urbanização de Belo Horizonte e a re-produção social das suas periferias metropolitanas: da irrupção à alienação das necessidades?
}

Luiz Antônio Evangelista de Andrade*

Resumo: Há uma necessidade teórica de se contribuir para o reconhecimento do estatuto da urbanização de Belo Horizonte, pensando-o a partir de suas periferias metropolitanas. Tais periferias se proliferaram na esteira da urbanização transformada em campo de negócios, cujas contradições daí advindas se materializaram nos embates pelas conquistas da urbanização. A não resolução das contradições faz com que outras se explicitem: a atualização das formas institucionalizadas daquilo que vem sendo chamado de bem-estar e realização da vida tem implicado numa insatisfação crescente com o cotidiano. Numa cotidianidade marcada pela abundância material sem precedente similar, floresce o obscurecimento das lentes que permitem pôr em questão essa cotidianidade.

Palavras-chave: Urbano; metropolização; periferias; dinheiro; mercadoria.

\section{THE URBANIZATION OF BELO HORIZONTE AND THE SOCIAL RE-PRODUCTION OF ITS METROPOLITAN OUTSKIRTS: FROM THE OUTBREAK TO THE ALIENATION OF THE NEEDS?}

Abstract: There is a theoretical need to contribute to the recognition of the statute of the urbanization of Belo Horizonte, thinking about it from its metropolitan outskirts. These outskirts, whose contradictions have materialized in the struggles for the achievements of urbanization, have proliferated in the wake of urbanization which was transformed into a business field. The lack of resolution of these contradictions makes others explicit: the update of the institutionalized forms of what has been called well-being and fulfillment of life has meant a growing dissatisfaction with everyday life. The obfuscation of the lens, which allow us to question this everyday life, grows due to an unprecedented material abundance.

Key Words: Urban; metropolitanization; outskirts; money; merchandise.

\section{Introdução}

Têm sido recorrentes em diversos meios de difusão do conhecimento o fenômeno usualmente denominado "expansão da classe C". De acordo com a Cetelem BGN, empresa ligada ao conglomerado financeiro BNP Paribas, em 2010 53\% dos brasileiros chegaram à "classe $\mathrm{C}^{\prime \prime}$, totalizando 101 milhões num universo de pouco mais de 190 milhões de habitantes. Em recente estudo, a Fundação Getúlio Vargas apontou que o "otimismo" vem despontando como "uma das características mais marcantes dos brasileiros", dada a sua enorme "confiança no futuro". Nas palavras do economista Marcelo Neri, coordenador do estudo, "O Brasil é um país cheio de problemas, mas está melhorando", posto que "A renda da população está crescendo mais que o Produto Interno Bruto e a desigualdade social está diminuindo". Além das razões inicialmente apontadas pelo economista, poderiam ser incluídos o "crescimento

* Graduado em Geografia pela Universidade Federal de Minas Gerais. Doutorando em Geografia pela Universidade Federal de Minas Gerais. Atualmente é professor do Ensino Básico, Técnico e Tecnológico do Instituto Federal do Espírito Santo (IFES). 
econômico", o "aumento da educação" e do "trabalho formal".

Afora a "abertura" para cobrar uma acepção mais ampla e rica das interpretações que reduzem a noção de classe social à "capacidade de consumo", as constatações acima poderiam inibir ou tornar fruto de algum delírio quaisquer tentativas de pôr em questão seus significados e significados. Afinal de contas, o Brasil, apesar de "cheio de problemas", "está melhorando", está conseguindo tornar consumidores milhões de brasileiros que, até há pouco tempo, dele estavam à margem.

Em que medida as constatações acima nos ajudam na tarefa de compreender a problemática urbana contemporânea a partir das periferias metropolitanas ${ }^{1}$, sem deixar de entender estas últimas como mote articulador de outros níveis e dimensões de análise do fenômeno urbano? Seria possível refletir sobre tais periferias via exame daquilo que no imaginário social de seus habitantes tende a aparecer como conquistas materiais, exemplificadas pela ampliação dos acessos aos diferentes "equipamentos" e "serviços" denominados aqui de infra-estruturas físicas e sociais ${ }^{2}$ ?

Tendo-se em conta que tais conquistas não são nenhuma bagatela histórica, isto é, simples produto de "favores" concedidos pelos governantes de plantão às hostes periféricas supostamente incapazes de fazerem história, poderíamos entendê-las como provenientes de lutas sociais que, paradoxalmente, deflagraram o ocaso da reflexão e de uma prática social com traços por vezes intensos de ação contra o Estado? É possível dizer que a urbanização de Belo Horizonte, mesmo tendo aprofundado seus dilemas e contradições não resolvidos, coincide com uma quadra da história marcada pelo arrefecimento das contestações outrora agudas contra o descompasso entre 0 prometido e o efetivamente realizado por essa sociedade?

Não obstante o aprofundamento de tais contradições, a idéia contemporânea de conquista social (e individual) vem se atualizando como melhora material determinada pelo acesso ao "mundo das mercadorias" e às infra-estruturas físicas e sociais, estando um e outro exemplo articulados à reprodução de relações sociais de produção ${ }^{3}$. No caso das periferias metropolitanas, em ampla medida a idéia de conquista - pelo menos entre aqueles que representaram ou representam os movimentos populares - parece se situar na crença de que haveria uma disposição do Estado em concedê-las através de suas políticas, algo que não encontraria precedente similar na história brasileira, pródiga em demonstrar sua "dívida social para com os pobres". Não é propósito desse ensaio a análise desta temática, não obstante valha ressaltar que as políticas de Estado apresentam-no como agente regulador do conflito de interesses na sociedade, em tese sem tomar partido de quaisquer um deles. Por conseguinte, seus programas e ações fundamentam concepções de "bem-estar" e de "realização da vida urbana", ambas coadunadas às representações da modernização como crescimento cuja reprodução quantitativa da riqueza abstrata é o fim a ser alcançado.

Julgamos importante refletir sobre a historicidade das conquistas mencionadas, tratando-as na perspectiva da satisfação e da reprodução ampliada de necessidades (HELLER, 1986) e quais são seus sentidos e significados atuais. Nessa quadra da história brasileira elas poderiam ser consideradas conquistas basilares do gênero humano porque fundamentais para as condições de bem-estar e realização da vida urbana? Mas de que modo essas representações que lhes 
alicerçam ganham conteúdo concreto nessa sociedade? Poder-se-ia dizer que esse conteúdo concreto estaria, num paradoxo apenas aparente, permeado por uma insatisfação crescente com o cotidiano?

Para tanto, para tratarmos dessa insatisfação, partiremos do pressuposto teórico e conceitual de que ela ganha contornos mais ou menos claros no curso da penetração diferencial do "mundo das mercadorias" na cotidianidade das periferias metropolitanas. Processo somado à privatização das relações sociais e à presença do trabalho abstrato e sobremaneira degradado, revelando-se aí uma crise estrutural de reprodução social.

\section{As periferias metropolitanas e} a negatividade da reprodução ampliada das necessidades sociais como carências

Numa das seções do capítulo dois de nossa pesquisa de mestrado (ANDRADE, 2010), propusemos descrever e analisar o "Alto Vera Cruz" com vistas a tentar compreender, a partir daquela realidade empírico-concreta localizada na porção Leste de Belo Horizonte, a sua formação enquanto espacialidade periférica no processo de urbanização contemporânea. Urbanização essa que, por um lado, trazia como parte de seu testemunho a acabrunhante formação de tais espacialidades no movimento geral de valorização do espaço nas centralidades de poder e riqueza de Belo Horizonte; por outro lado, pusemos a nu as modalidades de organização popular surgidas no Alto Vera Cruz, as conquistas daí advindas e os sentidos e significados atuais dessas conquistas para seus habitantes.

Nossa pesquisa partiu do entendimento de que a formação das periferias metropolitanas em Belo Horizonte pode ser apreendida, no nível do pensamento, através da compreensão das contradições sociais resultantes, entre outros aspectos, dos embates pela propriedade deflagrados alhures, quando da expulsão dos "indesejáveis" da área urbana da então recém-produzida capital de Minas Gerais. De maneira um tanto aligeirada, pode-se dizer que tais embates se circunscrevem à racionalidade mais geral atenazada à "lógica" da propriedade como arcabouço jurídico e institucional que se converteu numa variável econômica do capitalismo.

$$
\text { O desencadeamento dessas }
$$

contradições fez surgir, ao final da década de $1970^{5}$ em Belo Horizonte, uma nova qualidade das modalidades de organização popular eclodidas nas suas periferias metropolitanas. Tratou-se de um momento em que ganhou significação política junto às classes populares uma proposta de relação com o Estado a qual, pelo menos em tese, não estaria mais marcada pela tutela e pela dependência, mas forjada a partir da ação direta, visando pressioná-lo no sentido de prover reivindicações ${ }^{6}$, mormente de infraestruturas físicas e sociais. Reivindicações essas assentadas na idéia de "cidadania ativa", por meio da qual os diferentes movimentos sociais e organizações populares surgidas naquelas periferias em maior ou menor medida colocaram em questão o estatuto da reprodução de relações sociais.

Vera Telles (1987), ao fazer uma arguta reflexão sobre a literatura que se ocupou ao longo dos anos 1980 com a temática dos movimentos sociais, sublinha a ênfase teórica em demonstrar seu "signo de novidade". Compunha-se um cenário onde a "movimentação da sociedade civil", desfazendo-se das amarras tecnoburocráticas que a submetia aos ditames da privatização e da despolitização, inaugurava um modo de ser e de proceder na relação com o Estado que criava um campo de experiência sem precedentes. Nesse cenário, sinais de auto- 
instituição do popular eram enviados por esses movimentos sociais, pondo em questão as representações instituídas, aninhadas na Universidade ou no âmbito do Estado, atestando uma passividade e incapacidade "inerentes" à sociedade civil brasileira, fazendo dela, por excelência, "lugar" avesso à emergência de sujeitos políticos de fato. Sob um viés ideológico distinto, porém arbitrário nas considerações acerca das formas de organização popular, as instâncias tradicionais de representação política (partidos e sindicatos) viam essa possibilidade com forte ceticismo, a não ser pela sua intervenção "formadora de consciência".

Por se tratar de um texto escrito cerca de 10 anos depois do surgimento das primeiras organizações fora das amarras tradicionais de representação política, Telles chama a atenção para a necessidade tanto de não encampar argumentos celebratórios e desprovidos de uma análise que dialogue com a realidade empírico-concreta onde se constituem os movimentos populares, quanto de declarar esgotada sua força política, diluída na fragmentação e na dimensão epidérmica de seu campo de ação. Em vez de tratar essas duas facetas a partir de uma dicotomia ou como medida de verdade, poder-se-ia tomá-las como evidências que fazem ver "...o campo político em torno do qual esses movimentos se estruturam, algo que se configura numa relação de permanente conteúdo de tensão entre duas dinâmicas contraditórias" (TELLES, 1987, p.73).

Importante a pôr acento aqui é o fato de que tais lutas foram, no mais das vezes, tratadas pelo foco nas descrições do "fenômeno da globalização", nas "transformações no Estado", no "aumento da pobreza" e nas transformações do capitalismo devido à sua "crise econômica".
Esse foco encobre uma insatisfação erigida em meio às promessas não cumpridas por essa sociedade, mesmo quando sua reivindicação se localiza nas "questões econômicas" - leia-se materialidade, diminuição do custo de vida, geração de empregos etc.

Pode-se dizer que essas descrições, inadvertida ou deliberadamente, não trataram o fenômeno da crise para além do economismo, mesmo quando achavam que o estavam "superando". Ora, a crise é a condição crítica da reprodução do capitalismo enquanto formação econômica e social, da sua dificuldade - quiçá incapacidade - de reproduzir suas relações sociais constitutivas (LEFEBVRE, 2007). Com isso, as lutas sociais, na maior parte das pesquisas, não foram colocadas numa análise que contemplasse as estratégias do capitalismo de lidar com essas crises de reprodução, análise que deveria envolver, aí sim, as transformações no âmbito do Estado, as formas reprodutivas do capital (fluxos, produção de configurações espaciais, organização do trabalho e dos processos produtivos, entre outras), além do próprio "cenário da pobreza" e das estratégias contidas nas políticas de Estado visando seu "combate".

Tendo em vista o exposto acima, foi através da análise das modalidades de organização popular em Belo Horizonte em fins dos anos 1970 que nos propusemos questionar os sentidos e os significados das conquistas materiais de um modo geral presentes nas suas periferias metropolitanas. Junto a esse questionamento surgiu outro: afinal, tais conquistas ajudaram a transformar a vida de seus habitantes, tornála subjetiva e objetivamente diferente em relação à época de carência material absoluta?

Quando observamos a conquistas materiais no âmbito da aparência, é inegável 
que houve uma ampliação sobremaneira das possibilidades para o seu acesso. Uma fala recorrente entre os habitantes do Alto Vera Cruz quando por nós entrevistados sobretudo aqueles que vivenciaram diretamente as agruras advindas da precariedade ou da ausência do elementar da urbanização - referia-se à consideração de que, nos dias de hoje, "...tá tudo muito fácil!". A presença de linhas de ônibus, do asfaltamento das vias, da relativa presença do saneamento, de escolas, creches, da construção de conjuntos de apartamentos, dentre outras infra-estruturas físicas e sociais, ajudam na constatação objetiva das facilidades mencionadas pelos habitantes do Alto Vera Cruz.

Com efeito, é possível constatar que as conquistas materiais (tanto aquelas referidas às infra-estruturas físicas e sociais quanto aos chamados "bens de consumo") fornecidas pelas diferentes esferas de governo, não obstante sejam fruto de lutas sociais dotadas de maior ou menor radicalidade, devem ser situadas no âmago da modernização da sociedade, orientada pelo seu processo de industrialização e de urbanização. Isso equivale a dizer que elas melhoram a vida dos "atendidos", ao mesmo tempo em que ampliam sua inserção em diferentes níveis de relações sociais.

Duas vias de análise poderiam ser elencadas para ajudar na compreensão da inserção dos "atendidos" acima mencionada. A primeira delas, já bastante debatida por nós em outro momento (ANDRADE 2008), e, por isso mesmo, não faz parte de nossas ocupações nesse ensaio, refere-se à compreensão das chamadas "políticas sociais" ${ }^{7}$ na reprodução de relações sociais, as quais encontram no Estado - por meio de suas diferentes instituições - um de seus elementos mais ativos. É no conjunto da prática social que as instituições de Estado fornecem solidez aos arcabouços jurídicos e políticos que definem as normatizações diversas - por exemplo, as concepções de indivíduo, igualdade, liberdade e direito, esses fundamentos das relações de troca sob o capitalismo. Mas a reprodução de relações sociais não deixa de estar permeada por diferentes tensões e conflitos deflagrados na própria prática social. Como salienta Abensour (1998, p.57), o Estado é a permanente contradição entre sua "...intenção de universalidade, suas exigências racionais e suas pressuposições reais"

É essa contradição, mormente seus contornos concretos - por vezes virulentos que determina estratégias de Estado no sentido de arrefecê-las, as quais se direcionam àqueles subalterna e precariamente participantes da reprodução de relações sociais. Ao emprestarem seus desejos e suas vozes aos movimentos sociais e organizações populares, passam a reivindicar, com maior ou menor grau de radicalidade, outra forma de realização das conquistas do gênero humano. Em boa medida, as lutas sociais que eclodiram nas periferias metropolitanas de Belo Horizonte e de outras metrópoles brasileiras em fins dos anos 1970 e no transcurso dos anos 1980, expressaram essa contradição não resolvida, dando-nos um mote para buscar compreender os resultados dessa ação de Estado - e o novo quadro de contradições que a partir daí emergem.

A segunda via de análise implica considerar que as conquistas materiais se inscreveram na vida individual e social das periferias metropolitanas como disseminação de valores de uso submetidos aos termos do valor de troca. Isto posto, poderíamos tratálas em relação à sua historicidade, pois seriam caracterizadas, no tempo em que foram reivindicadas, como necessidades 
sociais referidas ao elementar da vida urbana, e hoje como "marcos fundadores" da "atualidade" da inserção dessas periferias no processo de modernização de Belo Horizonte. Dito de outro modo, tratar-se-ia da satisfação de necessidades que acabaram funcionando como uma espécie de viabilizadoras de necessidades de novo tipo, providas com base em critérios quantitativos, visto terem passado a aparecer no mercado como demanda solvente, reforçando a insatisfação. É importante considerar a materialidade e a imaterialidade - e sua presença ordinária na vida individual e social contemporânea enquanto coleção de mercadorias que se generalizam não só como atributos da troca, mas também como consequência do aumento da produtividade do trabalho, revelada pelo desenvolvimento das forças produtivas e sua submissão às relações de produção sob 0 capitalismo.

Descrevamos alguns aspectos relativos ao dinheiro e à mercadoria e a qualidade de sua presença nas espacialidades periféricas para ilustrar o que estamos chamando de historicidade das necessidades. A nosso ver, essa categoria de análise nos ajuda na apreensão do fenômeno da progressiva disseminação das necessidades sociais nas periferias como valores de uso submetidos ao universo das trocas quantitativas.

Pode-se dizer que, em muitos aspectos, o dinheiro não exercia sobre as espacialidades periféricas que foram se formando ao longo do processo de urbanização belohorizontino a centralidade que talvez nos últimos 15 ou 20 anos tem adquirido, até pelo fato dos rendimentos outrora percebidos pelos seus habitantes, na sua imensa maioria, não viabilizavam trocas quantitativamente mais complexas. Nessas periferias, devido à antiga precariedade que perfazia o processo de circulação do dinheiro- mercadoria e das mercadorias como um todo, uma fatia nada modesta da obtenção dos meios de vida pelos habitantes locais se construía numa cotidianidade na qual as trocas simples possuíam proeminência. Isso pode ser atestado, por exemplo, pelos relatos sobre a presença das hortas, das "criações", do recurso às compras através do "fiado" ${ }^{8} \mathrm{e}$ pelas fortes relações de parentela e de compadrio. Tratava-se de um modo de vida que, não obstante já estivesse entrecortado pelo estatuto do trabalho abstrato e da mercadoria, em alguma medida se reproduzia por fora da sociabilidade do valor, e, concomitantemente, produzia as representações acerca do "pertencer", do favor e das próprias trocas mediante a obtenção dos meios de vida.

Marx ([1857-8] 1987), no primeiro volume dos Grundrisse, realizou uma fina análise do transcurso histórico do dinheiro na sua transformação em forma monetária, e de como esta, ao penetrar na cotidianidade das formações sociais pré-capitalistas, destruía ou redefinia as relações sociais até então existentes, re-produzindo novas relações. Nesse sentido, o dinheiro, muito mais do que simples expressão monetária das trocas, passaria a produzir novos sentidos $e$ significados às relações sociais, paulatinamente determinando a produção, a circulação e o consumo das mercadorias determinando igualmente a produção e a satisfação das necessidades.

Ora, é na cotidianidade que se disseminam as representações ideológicas que associam o dinheiro ao bem-estar, precisamente porque aquele se objetiva pela reprodução de sua capacidade de orientar os vínculos sociais. No concernente ao poder social do dinheiro, que faz dele uma espécie de entidade transcendente e contribui ativamente para seu espraiamento sobre o conjunto da sociedade, Marx ([1844] 2004, 
p.159), nos Manuscritos econômicofilosóficos, faz a seguinte pergunta: "Se o dinheiro é o vínculo que me liga à vida humana, que liga a sociedade a mim, que me liga à natureza e ao homem, não é o dinheiro o vínculo de todos os vínculos"?

Trata-se, então, de compreender tais representações no contexto dos patamares técnico-produtivos atuais, diferentes daqueles da década de 1980, quando não estavam ainda dadas as condições da chamada "segmentação do consumo" nos diversos estratos populares, coincidindo com a generalização do acesso às mercadorias. Numa síntese ligeira, esse fenômeno se explica por dois motivos principais.

Primeiramente, o desenvolvimento das forças produtivas sob o capitalismo leva à constante revolução nas condições de produção de mercadorias, implicando nas diferentes mudanças tecnológicas, na reorganização dos processos produtivos e de trabalho, bem como nas vultosas transformações no âmbito da concorrência, chegando-se ao conjunto da reprodução de relações sociais. No tocante às transformações na organização produtiva, chama-nos a atenção o fenômeno que Marx ([1867] 1998), no segundo volume de $O$ capital, apreendeu teoricamente e denominou "leis de centralização do capital". Essa centralização pode ser inicialmente definida como um conjunto de mecanismos internos de controle dos processos produtivos - logo, se estendendo para as esferas da circulação e do consumo - com vistas a criar um (sempre frágil) equilíbrio entre tais processos e as "forças cegas de mercado". Estabelecem-se as premissas objetivas para que a busca pela mais-valia relativa corrobore a substituição, numa aceleração sem precedentes, dos elementos do capital fixo, aumentando igualmente o ritmo da sua desvalorização devido ao próprio patamar da concorrência. E a produção da mais-valia requer a submissão dos trabalhadores às leis da acumulação (divisão social e técnica do trabalho, aumento de produtividade, determinado patamar salarial etc), fazendo deles meros apêndices de um processo produtivo tecnológica e organizacionalmente cambiante ${ }^{9}$.

O segundo motivo é a conseqüência do dito acima: isso faz chegar às indústrias, empresas e ao consumidor doméstico a possibilidade de ambos terem acesso, respectivamente, aos elementos de capital fixo e de instrumentos do fundo de consumo (HARVEY, 1982). No caso destes últimos, a sua obsolescência física, consoante às estratégias de mobilização do imaginário social para as modas (do "modernizar-se"), é fundamental para a sua obsolescência econômica, sustentando-a. A criação do fundo de consumo se inscreve na $\mathrm{e}$ determina a reprodução da força de trabalho e também a reprodução social, ampliando as frentes de produção e realização da maisvalia. Acha-se aí imbricada a construção dos sentidos necessários para a submissão do homem que trabalha (ou que vive a incerteza diária da simples ocupação) às diversas pressões e repressões do cotidiano - sendo o próprio "ambiente" de trabalho pródigo em fornecê-las, pois se realiza encarcerando a vida individual e social aos seus tempos e espaços.

A ponto da percepção das gerações antigas no Alto Vera Cruz, captadas por nós através dos diálogos que com eles estabelecemos, ser a de que: "o dinhêro parece que compra mais coisa, né? Só ta difícil de ganhá, mas dá pra comprá umas coisinha melhó, né?". Mas a vida se tornou melhor sob quais pressupostos? Não é novidade teórica dizer que os indivíduos formulam representações sobre si e sobre o mundo, mas que estas são construídas e/ou resignificadas pela mediação de representações ideológicas atadas a uma 
estratégia de classe. Dito de outro modo, as percepções dos indivíduos se constroem em meio às suas reflexões sobre as vivências práticas e também dos respingos na cotidianidade das representações inscritas nos pressupostos da economia política, a qual se inscreve como determinação para a percepção do que é chamado de bem-estar e realização da vida nessa sociedade. Ambas as concepções se respaldaram pela unificação abstrata das necessidades sociais nos domínios do quantitativo - cuja resultante é a imensa acumulação de mercadorias (HELLER, 1986).

Ao se entranharem no ordinário da vida como norma social, tais necessidades definem, sob diversos matizes, os modos de satisfação a partir da troca mercantil, visto ser ela um dos imperativos do capital enquanto forma geral da riqueza tornada relação social. À medida que suprimem o desejo enquanto motor das necessidades sociais e 0 restringem às carências (necessidades controladas, cujo uso se degenera no valor de uso, um apêndice do valor de troca), esse desejo se ergue como resíduo, podendo (ou não) mobilizar questionamentos mais ou menos agudos frente à experiência prática.

É possível dizer que a relativa ausência das pressões ${ }^{10}$ exercidas sobre os indivíduos, resultantes dos processos que hoje os enredam numa miríade de circuitos produtivos e de consumo, tendia a ampliar as possibilidades da apropriação, nos termos de Lefebvre (1991, p.30), esse "...traço característico da atividade criadora, pela qual o que vem da natureza e da necessidade se transforma em obra, em um 'bem' para e pela atividade humana"? Trata-se de uma situação paradoxal só quando o olhar insiste em permanecer na sua aparência, dedicandoIhe toda atenção. Do contrário, uma contradição fundamental emerge: a apropriação, numa sociedade onde a riqueza socialmente produzida é continuamente expropriada, a apropriação só pode existir nos resíduos ainda não alcançados pela sua "lógica". Quando esta chega, o faz carreando para seus propósitos apenas aquilo que lhe é funcional. A apropriação se reduz com as pressões, convertendo-se contemporaneamente, dentre outros eufemismos para tratar a modernização, nas chamadas "potencialidades locais"...

A análise da generalização da forma mercadoria - alimentada pela forma da troca - e o estabelecimento de seu "mundo" sobre as periferias metropolitanas nos leva a evocar um importante pressuposto teórico. A mercadoria, nos diferentes modos de produção, assumiu formas históricas específicas nas representações sociais e nas práticas inscritas nos processos de objetivação do homem. Ao assumir, portanto, uma forma que the é própria no capitalismo, a mercadoria passou a ser o veículo a partir do qual o valor se valoriza e se torna a condição da produção da riqueza social - em detrimento do desenvolvimento do homem e da sociedade. Isso porque a mercadoria se "eleva" a uma forma "pura", assumindo a capacidade de ocultar as relações sociais envolvidas nesse processo; de ocultar, como nos diz Marx ([1867] 1998, I, p.94), "...as características sociais do próprio trabalho dos homens, apresentando-as como características materiais e propriedades sociais inerentes aos produtos do trabalho".

À reflexão sobre a mercadoria não corresponde tratá-la como forma dissociada dos conteúdos sociais que ela oculta e, ao mesmo tempo, traz à tona, sob outros significados. As formas, mesmo sendo produto da idéia abstrata advinda de instituições e de classes sociais, necessitam de suportes sensíveis e materiais, não obstante estes não Ihes sejam suficientes. A 
materialização que abriga as formas é também uma resultante delas. A sua concretude social reforça sua qualidade abstrata (mental), haja vista que se impõe mediante os atos e ações ordinários da cotidianidade.

Ademais, a especificidade histórica das formas mercadoria e dinheiro faz delas suportes e condicionantes de relações sociais fundamentais. Sendo o dinheiro a medida imanente do valor das mercadorias (MARX, [1867] 1998), e partindo do pressuposto de que ambas essas formas se universalizam e colonizam as práticas individual e social, mesmo o âmbito mais irrisório destas de alguma maneira vem expresso por aquelas. Há uma "corrosão do caráter" cuja tendência ganha uma silhueta mais clara em proporção à amplitude com a qual o dinheiro assume a primazia entre tais práticas, demarcando com seu ferrolho a lógica monetária identificada "...con la venalidad y [la] corrupción generales" (MARX [1857-58] 1987, I, p.90.

Eis a elevação da circulação do capital às últimas conseqüências, alimentando relações sociais monetarizadas, precisamente porque o dinheiro tem de se propagar como medida de tudo, deixando às margens os elementos residuais e práticas sociais a ele não diretamente referidas. Todavia, o dinheiro e a mercadoria como modos de existência do valor não fazem sobre os modos de vida um percurso lógico, pois não chegam de uma vez por todas, mas de maneira progressiva no espaço e no tempo.

Assim sendo, é possível dizer que a forma mercadoria (e também a mercadoriadinheiro) oscilava entre o lugar apenas periférico no conjunto das práticas sociais dando margem para que estas assumissem sentidos muitas vezes vigorosos e intensos e uma espécie de "centralidade relativa", pois se impunha na cotidianidade da maioria dos habitantes do Alto Vera Cruz, obrigando os membros adultos das famílias (e até os mais jovens, com os pequenos serviços) a auferirem rendimentos ou salários para a simples reprodução familiar, ou até dar significado à idéia de conquista e de mérito alcançada pelo trabalho de "sol a sol". O momento da vida tido como do "nãotrabalho", isto é, não dedicado, por exemplo, ao chão da fábrica ou à "casa de família", era vivido num misto de dificuldades objetivas não raro extremas e de saídas criativas para tais dificuldades, encerrando aspectos do lúdico - e, certamente, das confusões e conflitos entre vizinhos ou familiares por vezes sérios.

Já foi dito que a ampliação da norma social do consumo para os estratos sociais populares não se faz sem a igual ampliação, em extensão e profundidade, da monetarização entre tais parcelas e na sua dependência das formas sociais do trabalho (abstrato). A reprodução ampliada da proletarização coincide com a dependência do dinheiro em um número cada vez maior de situações, a ponto dos diferentes membros da família terem sido premidos, sobretudo nas últimas três décadas, a aumentar sobremaneira sua jornada de trabalho para dar fôlego ao orçamento doméstico. Afinal de contas, este último tem sido sumamente afetado pelo vertiginoso aumento dos impostos ${ }^{11}$, incidindo sobre as condições para a reprodução familiar ou ao provimento das necessidades e carências incorporadas por muitas dessas famílias.

Some-se às dificuldades de reprodução familiar o fato dos quintais (onde o cultivo de hortaliças e de "criações" como porcos e galinhas era presença quase certa) estarem sendo ou terem sido utilizados na construção de "puxadinhos", inviabilizando a economia doméstica produtora de valores de uso e jogando as pessoas nos circuitos das trocas mercantis. Por conseguinte, nos 
últimos anos a busca por tais valores de uso tem se dirigido ao consumo de mercadorias nos supermercados, presença que vem aumentando gradativamente no Alto Vera $\mathrm{Cruz}^{12}$. Trata-se de um resultado e ao mesmo tempo de um imperativo para que as famílias viabilizem ganhos monetários visando fazerem frente a esse modo de vida. Modo de vida carregado de representações do "moderno", fazendo oposição àquilo que é tido como "arcaico" - note-se que o cultivo de hortaliças ou de "criações" no quintal é visto por muitos jovens como próprio de "gente da roça", e, no caso das pessoas de idade mediana que têm "vivido para trabalhar", "num tê tempo" ou "num tê mais espaço no quintal de casa".

A emergência e a consolidação nas periferias metropolitanas dessa sociabilidade marcada por indivíduos monetarizados e sem dinheiro de maneira alguma é paradoxal. Ao contrário, ela bem demonstra os fundamentos da reprodução social contemporânea: ao se esfumarem as perspectivas de futuro, demarcadas pela construção de projetos de vida a médio e longo prazos que a própria sociedade burguesa outrora cuidou de dar sentido (a unificação entre trabalho, a família e a propriedade), é o "aqui e agora", os momentos de euforia, a tendência ao prazer fugaz e sem intensidade que toma conta das subjetividades. $O$ imediatismo nos revela a fluidez e a obsolescência cujas marcas estão cravadas numa constante falta, nunca preenchida. Valer-se dos diversos signos de consumo, mais do que uma demonstração de "bem-estar" ou poder, escancara um estado de ausência de perspectivas mesmo dentro do já aludido projeto burguês de vida. Martins (2002), acerca da "inclusão social" proposta pelos grupos "progressistas", assinala como este se coaduna com o ideário contemporâneo do "bem-estar":
"A grande mudança social havida desde o apogeu do ideal da ascensão social dos pobres por meio do trabalho, nos anos cinqüenta, é que a ascensão, nos grandes centros onde se acumula a pobreza, já não passa pela mediação da propriedade imobiliária e pelo enraizamento, como outrora. Agora passa pelo consumo e pela propriedade mobiliária: o carro, a roupa, os eletrodomésticos. Quase que se pode dizer que houve uma opção consciente pelos signos de consumo em detrimento dos signos de propriedade, da moradia e da alimentação" (MARTINS, 2002, p.36) $)^{13}$

As conseqüências do gradual aumento das dificuldades para a reprodução individual e familiar por fora ou pelo menos sem que o dinheiro seja a determinação central têm sido devastadoras, reverberando na deterioração ou no esfacelamento de muitos vínculos familiares ou de solidariedades entre vizinhos no Alto Vera Cruz. Famílias inteiras têm sido acometidas pela quase inviabilização de sua reprodução, haja vista que os ganhos monetários não raro vêm se restringindo àqueles percebidos pelos avós, na forma de benefício de aposentadoria ou de pensão. O trabalho ou a ocupação esporádica, quando existem, obrigam aquele ou aquela na família que o exercem a passar grande parte do seu tempo em longas jornadas e também nos trajetos pela metrópole. Os salários ou rendimentos muitas vezes mal têm dado para arcar com todas as despesas. Preocupações objetivas, como a tarifa de energia elétrica ou de água por vencer e os alimentos de primeira necessidade (alvo de constantes oscilações de preços) por comprar, contribuem para tornar nos dias de hoje o desempregado ou a desempregada na família um problema que muitas vezes não se pode ou não se quer enfrentar. 


\section{Para não concluir: o político} nos meandros da tensão entre alienação e desalienação

As feições assumidas pelas relações que o homem - no processo histórico em meio ao qual ele se levantou da sua animalidade - foi estabelecendo consigo mesmo, com os outros homens e com a natureza, no transcurso da formação social calcada na produção da riqueza abstrata, passaram a produzir formas particulares de alienação. A condição humana na historicidade do capital paulatinamente se consolidou como embotamento ou a perda da capacidade do homem de exercer sua liberdade por meio do uso e da apropriação.

Seria possível construir um processo de superação da alienação, seria possível realizar a liberdade humana? Mészaros (2006, p.149) compreende a liberdade humana não como "...a negação daquilo que é especificamente natural no ser humano uma negação em favor do que parece ser um ideal transcendental - mas, pelo contrário, sua afirmação". Evocamos o propósito moral contido na reflexão teórica marxiana, o qual nega qualquer transcendentalidade do humano - negando, por exemplo, um suposto caráter egoísta do homem como atributo de sua natureza (MARX [1844], 2004). Nesse caso, à medida que as abstrações forjadas pela economia vulgar se objetivam como formas sociais negadoras dos conteúdos necessários à sua compreensão, encarnando o repetitivo e o ordinário (no quadro da cotidianidade), viabilizou-se a "verificação" desse "caráter egoísta" do homem. Ocultaram-se as condições históricas e sociais que tornaram os homens egoístas, dando-se primazia à sua aparência fenomênica.

Alguns ideólogos afirmariam, ao atualizarem a premissa de muitos economistas políticos dos séculos XVIII e
XIX, que a principal qualidade "liberdade" burguesa é o fato dela ser o "ápice" da reunião das plenas condições para o homem exercer seu "livre direito de escolha", consoante à "livre iniciativa" e à "livre empresa" tão aclamadas pelas ideologias morais do pragmatismo e do utilitarismo. Por conseguinte, essas ideologias dão respaldo às teses acerca de uma "natureza egoísta" dos homens que precisa ser potencializada ou, na pior das hipóteses, é-lhe "inerente".

Não é à toa que tais prejuízos se objetivam na prática social, por exemplo, através do tão em voga ideário da "competitividade", da "flexibilidade" e do "dinamismo", o qual "preenche", de uma maneira muito especial, o imaginário social, sobretudo no que tange à incidência de suas manifestações na juventude. Nas periferias metropolitanas esse ideário "convida" os jovens a "buscarem seu futuro" no mundo do trabalho abstrato, garantindo ao menos a "empregabilidade" que lhes escapa dos dedos, pois o atual ritmo da mudança tecnológica impõe uma obsolescência de "qualificações" sumamente mais rápida. Deve-se tirá-los da "vulnerabilidade" e do "risco". "Inclusões sociais" que nada mais são do que a institucionalização da divisão do trabalho, com todas as suas articulações e conseqüências nefastas.

A atualização contemporânea da idéia de "liberdade" faz dela sinônimo de liberdade individual degradada, visto não ser liberdade que só se realiza na e através da liberdade do outro. Eis aí a liberdade como algo exterior ao humano, corroborando a sua fixidez, a sua transcendentalidade e a prevalência da satisfação das necessidades a partir de uma concepção estreita de bem-estar, feita às custas das melhores energias criativas humanas. O tema da liberdade só pode se formulado quando pensamos em liberdade humana (MARX, [1844] 2004). 
Entendemos ser urgente a qualificação dos debates acerca do vem sendo chamado de "direitos", donde se demarcam as noções de "conquista" e "bemestar". Temos percebido que os argumentos em torno da insuficiência das modalidades tradicionais dos direitos passam menos pela analise dialética de suas contradições do que pelo imobilismo lógico centrado na universalização ou na focalização. Mais do que discussões que não avançam para além da aparência fenomênica da relação contratual estabelecida nos e pelos direitos sociais, precisamos de nos perguntar se estes últimos foram e têm sido capazes de alicerçar uma transformação qualitativa da vida - por dentro de outra racionalidade que não a da valorização abstrata das coisas.

Talvez seja preciso retomar teórica e praticamente a senda trilhada por muitos movimentos sociais desde fins do século XIX, quando suas lutas expressaram as divergências e conflitos entre a criação de direitos sociais e a sua consolidação como passo para o estabelecimento de outras relações com a produção, com o trabalho, com a propriedade e com as necessidades. E essa retomada pressupõe um debate inicial que atente para as reduções e estrapolações dentro do campo institucionalizado que se arroga na prerrogativa de pôr e dispor sobre aquilo que são e devem ser os direitos corroborando a sua destituição ocultada nos argumentos frágeis (não obstante sua força institucional) que apregoam os limites da universalização.

$\mathrm{E}$ isso acontece porque operam pela indistinção (inadvertida ou deliberada) entre particularismos e diferenças. Os primeiros são percebidos isoladamente, o que dá margem para argumentos que trazem a noção de direito como algo em si, isto é, só observam sua versão burguesa, centrada em concepções estreitas de bem-estar e realização da vida, essas sim homogeneizadoras. Uma noção de direito que dê margem para 0 entendimento das diferenças nas suas relações (tendo-se em conta suas particularidades) deve superar a si mesma; deve pôr em questão tal concepção para ampliá-la - indo além dos seus próprios formuladores e de seu compromisso com a reprodução das relações sociais de produção.

O indivíduo só se constrói socialmente dentro de princípios que o integrem a uma rede de igualdade social que Ihe dê plena autonomia ao exercício de suas capacidades diferenciais. Do contrário, "...a alienação surge como um divórcio entre o individual e o social, entre o natural e autoconsciente" (MÉSZAROS, 2006, p.160). A única determinação colocada ao homem enquanto ser que se levanta da sua animalidade estabelecendo relações sociais é que ele é um Ser natural humano, um Ser de necessidades e poderes, histórica e socialmente constituídos. O que nos faz refletir sobre a relação histórica e social do homem com tais necessidades e poderes. Aquele os realiza tanto na sua sobrevivência quanto nas suas necessidades de fruição. Daí a idéia de que o homem é um Ser natural humano, visto que as propensões naturais do homem tornaram-se propensões humanas no transcurso da sua historicidade.

A concepção homogeneizadora aludida tende a suprimir as diferenças e a sua qualidade de conhecimento do imediato concernente ao cotidiano por parte das classes populares. Isso porque ela opera naquilo que seria a construção nunca acabada de uma sociedade forjada pelos princípios políticos que denotam a democracia radical. Sociedade essa calcada na provisão efetiva de direitos e no direito a criá-los como condição socialmente definida no e pelo político, o qual se realizaria 
cotidianamente por sujeitos racionais e livres

como necessidades radicais (HELLER, 1986), não mais como expressão das definições

petrificadas de política imersas na

institucionalidade do poder.

Enfim, reivindicar uma liberdade

verdadeiramente humana (a partir de uma

discussão qualificada de direitos), como disse

\section{NOTAS}

${ }^{1}$ Cumpre enfatizar que não tomamos a noção de periferia como resultado de uma "constatação lógica" que endossa a sua separação permanente daquilo que seriam as centralidades (de poder e de riqueza). Tais centralidades podem, inclusive, serem redefinidas, destruídas ou criadas na esteira de acumulações primitivas do espaço mediante estratégias de valorização que canalizam em seu favor espacialidades até então "desinteressantes" ao capital. Além dessa premissa, na nossa perspectiva de análise a periferia é metrópole, vivendo suas contradições específicas, mas também as contradições mais gerais advindas do curso da re-produção das relações sociais da e na metrópole. Por isso mesmo, a periferia também é centralidade: as contradições materializam-se nos embates, podendo fazer dessas espacialidades o lugar onde o político irrompe, ganhando e dando sentido às práticas de seus habitantes, as classes populares.

2 De acordo com Harvey (1982) essas infra-estruturas, ao viabilizarem a transferência temporal do valor pela via de investimentos, tornam-se importantes estratégias do capitalismo no sentido de lidar com crises de reprodução cada vez mais recorrentes. Nos termos do autor, as infra-estruturas físicas e sociais: "Regulan los contratos, el intercambio, el dinero y el crédito, así como la competencia entre los capitalistas, la centralización de capitales, las condiciones del trabajo (como la jornada de trabajo) y vários otros aspectos de la relación entre el capital y el trabajo. A menudo definen determinadas estructuras de la lucha de clases. Proporcionan los medios para obtener conocimientos científicos e técnicos, nuevas técnicas administrativas y nuevos medios para facilitar el cobro, almacenamiento y comunicación de la información. También abarcan la serie de instituciones que contribuyen a la reproducción da fuerza de trabajo (servicios de salud, educación, servicios sociales, etc) y a la vida cultural en todos sus matizados aspectos (incluyendo los de la burguesia). Ofrecen medios de control ideológico así como foros para el debate ideológico. Algo más siniestro son los medios de vigilancia y represión, que siempre son el último recurso cuando la sociedad se ve empujada al interior de la caldera de un fiero conflicto de clases" (HARVEY, 1982, p.401-2).

${ }^{3}$ Para Lefebvre (2008,p.47-8): "Essa re-produção das relações de produção não coincide mais com a reprodução dos meios de produção; ela se efetua por meio da cotidianidade, através dos lazeres e da cultura, através da escola e da universidade, através das extensões e proliferações da cidade antiga, ou seja, através do espaço inteiro".

${ }^{4}$ A idéia de degradação do trabalho aqui tem estatuto conceitual, na medida em que ela apreende a forma histórica do trabalho sob o capitalismo a partir do momento em que o mesmo se dá pelo assalariamento, uma das resultantes do processo de separação dos homens dos meios de produção e reprodução de sua vida. Não tratamos do trabalho com base numa concepção legalista de direitos (baseada na idéia de cidadania que compõe a esfera pública burguesa), opondo formal/informal, boa/más condições de trabalho, etc.

${ }^{5}$ Embora a periodização da nossa descrição do nascedouro de modalidades de organização popular nas vilas e favelas de Belo Horizonte esteja focada em fins da década de 1970, não podemos deixar de mencionar aquelas surgidas ainda na década de 1950, oriundas das constantes ameaças de remoção de seus habitantes da parte do poder "público", justificadas pela reintegração de posse (calcadas no sacro "direito de propriedade") e/ou pela execução de obras de infra-estrutura. Entre tantas outras formas de organização popular surgidas no referido período, podemos citar as "Associações de Defesa Coletiva", surgidas em meados da década de 1950 e apoiadas por setores progressistas da base da Igreja Católica, e a "Federação dos Trabalhadores Favelados de Belo Horizonte", surgida no início da década de 1960.

${ }^{6}$ Para uma descrição do (novo) processo de politização das classes populares em Belo Horizonte, a partir da década de 1950, ver Somarriba (1984) e Afonso e Azevedo (1987).

7 As políticas sociais no município de Belo Horizonte correspondem, de maneira genérica, ao conjunto das políticas de assistência social, abastecimento, esportes, trabalho e direitos de cidadania, além dos programas de "transferência de renda" conveniados com o Governo Federal, como o "Bolsa Família". 
${ }^{8}$ Com efeito, a presença do "fiado" na cotidianidade das periferias metropolitanas no mais das vezes se constituía numa forma não centrada nas trocas tipicamente capitalistas para se lidar com a expansão das formas monetarizadas das relações sociais.

9 Cumpre enfatizar que as leis de centralização do capital e a mudança tecnológica são desdobramentos das antinomias fundamentais da produção de mercadorias - ao mesmo tempo em que esta última se constitui como sua unidade: o valor de uso e o valor de troca.

${ }_{10}$ Não estamos com a afirmação acima querendo dizer que não havia sobre os ombros das pessoas que passaram a habitar o antigo "Alto dos Minérios" (primeira denominação do Alto Vera Cruz) como opção de vida numa "cidade" que se transformou em metrópole na esteira dos negócios com a urbanização, o enorme peso da proletarização. Essa condição de maneira alguma é por nós negada, como se percebe ao longo de todo o nosso texto. Ao contrário, queremos dizer que tal condição em boa medida acabou trazendo significados intensos às práticas sociais no e com o espaço estabelecidas por aqueles habitantes, até mesmo devido à precária presença do dinheiro entre eles.

${ }_{11}$ De acordo com matéria publicada pelo jornal Hoje em dia, no dia 01 de julho de 2009: "As famílias pobres têm que trabalhar quase o dobro das famílias mais ricas para arcar com os impostos cobrados no Brasil. O diagnóstico é do Instituto de Pesquisa Econômica Aplicada (IPEA), que calcula que, enquanto famílias com renda mensal de até dois salários mínimos ( $R \$ 930)$ despendem 197 dias do ano só para pagar tributos, as famílias com renda superior a 30 salários mínimos (R\$13.950), levam 106 dias para saldar as obrigações com o Fisco. Na média, o brasileiro gasta 132 dias de trabalho por ano só para pagar impostos. O levantamento concluiu que os $10 \%$ mais pobres do país destinam $32,8 \%$ da sua renda para o pagamento de impostos, enquanto os $10 \%$ mais ricos gastam $22,7 \%$. 'Quem tem mais dinheiro paga menos impostos', afirmou o presidente do IPEA, Marcio Pochmann, que divulgou o estudo, que classifica a situação como 'iníqua'".

${ }^{12}$ Já faz alguns anos que a rede de supermercados " $\mathrm{BH}^{\prime}$, uma das redes varejistas que mais cresce em Minas Gerais, possui uma loja no Alto Vera Cruz, sendo esta uma das campeãs de venda entre suas cerca de 100 lojas.

${ }_{13}$ Só não podemos levar às últimas conseqüências o olhar do autor no concernente às formas da propriedade. Não obstante sua "conquista" seja, de fato, mais difícil que a do carro, da roupa ou dos eletrodomésticos, ela ainda é pleiteada mesmo por aqueles hoje vivendo a generalização do espetáculo como representação do falso tornada "real". Numa periferia como o Alto Vera Cruz, as reuniões convocadas pela Associação Comunitária, quando a pauta envolve os trâmites da regularização fundiária, têm presença quase sempre maciça de interessados.

\section{REFERÊNCIAS BIBLIOGRÁFICAS}

ABENSOUR, Miguel. A democracia contra o Estado: Marx e o movimento maquiaveliano. Belo Horizonte: Editora UFMG, 1998. 147p.

AFONSO, Mariza Resende; AZEVEDO, Sérgio de. Cidade, poder público e movimento de favelados. In: POMPERMAYER, Malori (Org). Movimentos sociais em Minas Gerais: emergências e perspectivas. Belo Horizonte: Editora UFMG, 1987. p.111-139.

ANDRADE, Luiz Antônio Evangelista de. Espaço, política e periferia: as políticas sociais na re-produção das relações sociais de produção. Terra Livre. Dourados, Ano 24, v. 2 no 31. Jul/dez 2008. P.33-48.

ANDRADE, Luiz Antônio Evangelista de. Espaço e reprodução social na periferia da metrópole de belo horizonte: a experiência da "família popular". 2010, 301p. Dissertação (Mestrado em Geografia) Instituto de Geociências da Universidade Federal de Minas Gerais, Belo Horizonte.

HARVEY, David. Los limites del capitalismo y la teoria marxista. México: Fondo de Cultura Econômica, 1982. 469p.

\begin{abstract}
HELLER, Agnes. Teoría de las necessidades en Marx. Barcelona: Ediciones Península, 1986. 183p.
\end{abstract}

LEFEBVRE, Henri. A vida cotidiana no mundo moderno. São Paulo: Ática, 1991. $216 \mathrm{p}$.

LEFEBVRE, Henri. Espaço e política. Belo Horizonte: Editora UFMG, 2008. 190p.

LEFEBVRE, Henri. A produção do espaço. Tradução de Doralice Barros Pereira e Sérgio Martins. [S.i.:s.n.], 2007. Inédito. Título original: La production de l'espace. $4^{\mathrm{a}}$ ed. Paris: Éditions Anthropos, 2000).

MARTINS, José de Souza. O falso problema da exclusão e o problema social da inclusão marginal. In: MARTINS, José de Souza. A exclusão social e a nova desigualdade. São Paulo: Paulus, 1997. p.25-38.

MARX, Karl. Elementos fundamentales para la crítica de la economía política 
(Grundrisse) 1857-1858. Volume 1. México: Siglo veintiuno editores, 1987. 544p.

MARX, Karl. O capital: crítica à economia política. Livro 1, Volume 1: o processo de produção do capital. Rio de Janeiro: Civilização Brasileira, 1998. 572p.

MARX, Karl. Manuscritos econômicofilosóficos. São Paulo: Boitempo editorial, 2004. $175 p$.

MÉSZAROS, Istvan. A teoria da alienação em Marx. São Paulo: Boitempo editorial, 2006. 293p.
SOMARRIBA, Maria das Mercês. Lutas urbanas em Belo Horizonte. Petrópolis: Vozes, 1984. 130p.

TELLES, Vera da Silva. Movimentos sociais: reflexões sobre a experiência dos anos 70 . In: SHERER-WARREN, Ilse; KRISCHKE, Paulo J. (Orgs). Uma revolução no cotidiano? Os novos movimentos sociais na América do Sul. São Paulo: Brasiliense, 1987. p.54-85. 